\title{
The Glass-Molding Process for Planar-Integrated Micro-Optical Component
}

\author{
Chien-Yao HuAnG ${ }^{1,2 *}$, Jyh-Rou SzE ${ }^{1}$, Kuo-Cheng HuAnG ${ }^{1}$, Chao-Hui KuO ${ }^{1}$, \\ Shih-Feng TSENG ${ }^{1,2}$, and Chang-Pin $\mathrm{CHOU}^{2}$ \\ ${ }^{1}$ Instrument Technology Research Center, National Applied Research Laboratories, \\ 20, R\&D Rd. VI, Hsinchu Science Park, Hsinchu 300, Taiwan \\ ${ }^{2}$ Department of Mechanical Engineering, National Chiao Tung University, \\ 1001 University Road, Hsinchu 300, Taiwan
}

(Received May 28, 2010; Accepted November 1, 2010)

This paper presents a precision glass-molding process to fabricate planar-integrated micro-optical components (PIMOC) applied to a micro projection display system, optical interconnection system and optical storage system. The PIMOC was designed based on wave propagation theory, and fabricated using a glass molding process. Experimental results are discussed in this article. The experiment showed that the PIMOC fabricated in a vacuum environment meets the design value with precision glass-molding technology (PGMT) at a molding force of $2.75 \mathrm{kN}$, a molding temperature of $750^{\circ} \mathrm{C}$ and a cooling rate of $49^{\circ} \mathrm{C} / \mathrm{min}$. (C) 2011 The Japan Society of Applied Physics

Keywords: precision glass-molding technology (PGMT), planar-integrated micro-optical component (PIMOC)

\section{Introduction}

Previous literature presented the development of precision glass-molding technology (PGMT) in the mass-production of optical components. ${ }^{1-6)}$ The planar-integrated microoptical component (PIMOC) consists of multi-optical elements with specific profiles. Because various optical elements can be combined into PIMOC, PIMOC reduces the size of an optical system, such as the micro-projection display, optical interconnection system and optical storage system. There are three methods for fabricating a glass lens; a computer numerical control (CNC) grinding process, precision diamond grinding process, and PGMT. Because the upper profile of PIMOC is concave, it is very difficult to fabricate PIMOC using a precision diamond grinding process. Furthermore, the $\mathrm{CNC}$ grinding process is a traditional technique that takes several days to generate a PIMOC. Therefore, both techniques are not the ideal massproduction method. ${ }^{7)}$ There are several advantages of PGMT, such as short cycle time, high accuracy, and high freedom. However, the PGMT is not only able to fabricate PIMOC with the cycle time of 30 minutes but also able to enhance PIMOC surface quality. Thus, this paper presents the fabrication of high quality PIMOC using the PGMT process, which can be mass-produced.

\section{Fabrication}

The ray tracing approach was used to optimize the profiles of functional PIMOC surfaces. Using optical simulation software and wave propagation theorem, the optical parameters of PIMOC were obtained. The parabolic surface of the tungsten carbide (WC) mold was made using precision diamond grinding technology. To reduce adhesion to the WC mold surface, the mold was coated with Pt-Ir film. The

\footnotetext{
*E-mail address: msyz@itrc.narl.org.tw
}

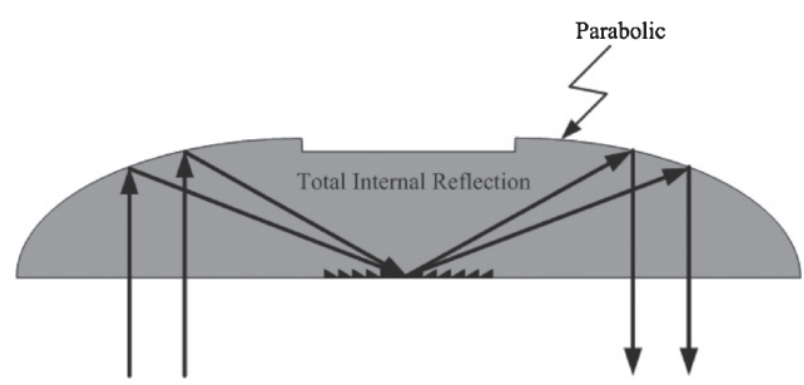

Fig. 1. Light path of PIMOC.

optical performance of PIMOC depended on the roughness and geometric deviation of the functional surface. So, parameters must be controlled during the PGMT process.

In this study, the radius of the upper parabolic surface was $42 \mathrm{~mm}$ and its corresponding conic constant was -1 . The parabolic surface was coated with $\mathrm{Ag}$ or $\mathrm{Al}$ film to improve the reflection on the total internal surface. The incident beam, reflected by the parabolic surface, focused directly on the microstructure of the bottom surface. The diffracted beam was then reflected back using the parabolic surface and exited through the bottom plane. Figure 1 shows the complete light path of PIMOC.

In the experiment, PIMOC was fabricated using N-BK7 glass in a Toshiba $207 \mathrm{HV}$ machine. Because the glass transition temperature $\left(T_{\mathrm{g}}\right)$ of N-BK7 was $557^{\circ} \mathrm{C}$, the heated temperature and the molding pressure of PGMT process were set at $690-750^{\circ} \mathrm{C}$ and $0.25-2.75 \mathrm{kN}$, respectively. To avoid the bubbles or voids generated on the surface of PIMOC, the process was performed in a vacuum environment. Figure 2 shows the temperature and pressure of the PGMT process with respect to cycle time. The cooling rate was the critical parameter as can be seen when looking at the adjusted parameters of PGMT, shown in Table 1. If the 


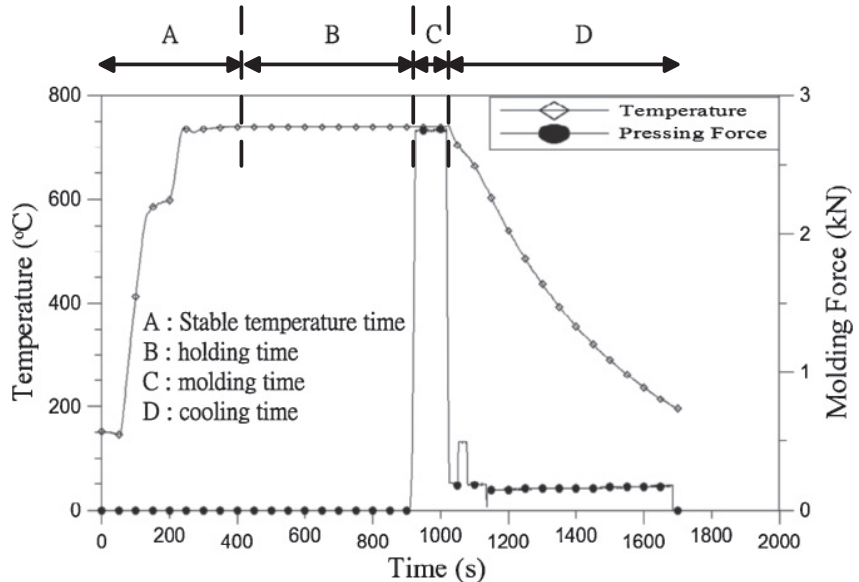

Fig. 2. Temperature and pressure of PGMT process with respect to cycle time.

Table 1. Adjusted parameters of PGMT process.

\begin{tabular}{ll}
\hline Temperature $\left({ }^{\circ} \mathrm{C}\right)$ & 750 \\
Molding force $(\mathrm{kN})$ & 2.75 \\
Temperature holding time $(\mathrm{s})$ & 500 \\
Environment & Vacuum \\
Time $(\mathrm{min})$ & 29 \\
Cooling rate $\left({ }^{\circ} \mathrm{C} / \mathrm{min}\right)$ & 49 \\
\hline
\end{tabular}

cooling rate was too fast $\left(>50^{\circ} \mathrm{C} / \mathrm{min}\right)$, the residual stress induced the PIMOC to crack.

\section{Results and Discussion}

The fill rate $(f r)$ is defined using the ratio of glass depth $\left(d_{\mathrm{g}}\right)$ and mold depth $\left(d_{\mathrm{m}}\right)$ as follows:

$$
f r=\frac{d_{\mathrm{g}}}{d_{\mathrm{m}}} .
$$

If the fill rate does not reach $100 \%$, a bubble defect exists in the PIMOC. The profiles of PIMOC are measured using a Keyence VK9700 confocal microscope; the corresponding fill rates are given in eq. (1). Finally, the optimum fabrication parameters were obtained after several PGMT cycles.

The relationship between the molding temperature, pressure and fill rate of PGMT is shown in Fig. 3. The fill rate reached $100 \%$ when molding pressure was $2.75 \mathrm{kN}$. When the molding temperature range was controlled between 690 to $750{ }^{\circ} \mathrm{C}$, the adhesion of the glass material decreased with increased temperature. Therefore, the glass material was easily deformed at higher temperature. The decreased adhesion caused the deformation of PIMOC and increased the fill rate. The fill rate increased linearly while the molding temperature increased from 690 to $750^{\circ} \mathrm{C}$. The fill rate reached $100 \%$ when the molding temperature was $750^{\circ} \mathrm{C}$.

The bubbles and cracks in the PIMOC resulted in noncontinuous PIMIC profiles, as shown in Fig. 4(a). During the PGMT process of PIMOC, it was necessary to remove the

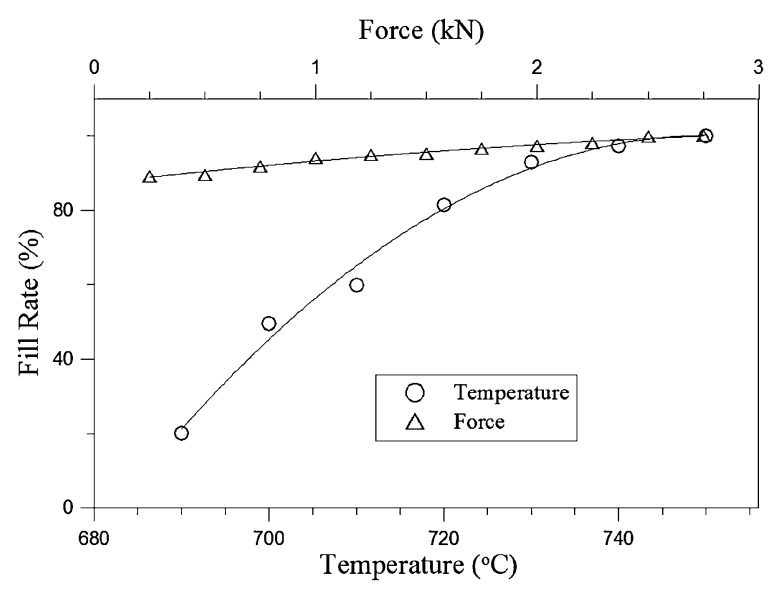

Fig. 3. The relationship between molding temperature/force and fill rate.

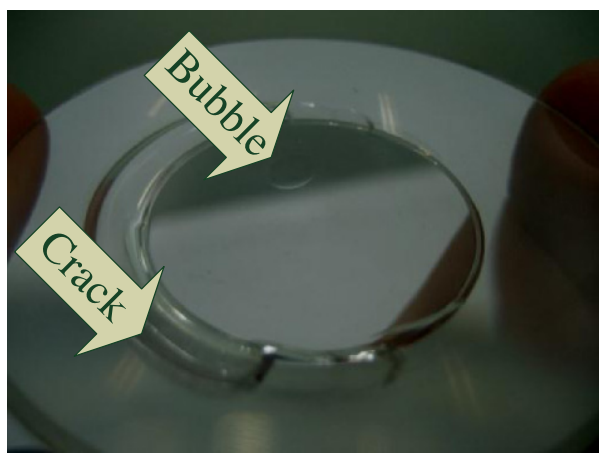

(a)

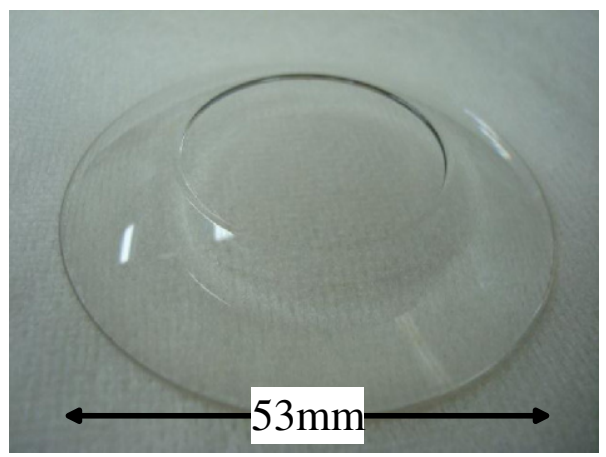

(b)

Fig. 4. (Color online) The PIMOC photography.

bubbles and cracks by controlling of molding parameters. The optimization conditions, such as reducing the cooling rate below $50^{\circ} \mathrm{C} / \mathrm{min}$ and operating PGMT in a vacuum environment were useful in avoiding cracks and bubbles The photograph of PIMOC with optimized fabrication parameters is shown in Fig. 4(b). The surface profile of PIMOC was measured using the precision confocal microscope, and the measured result is shown in Fig. 5. If the upper profile of PIMOC adheres to the design value, the fill rate was $100 \%$. 


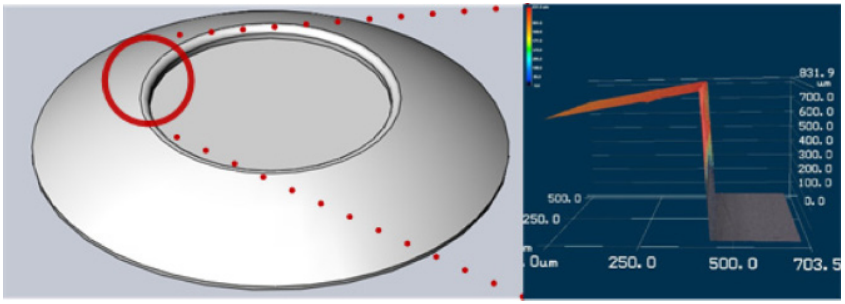

Fig. 5. (Color online) The upper profile of PIMOC.

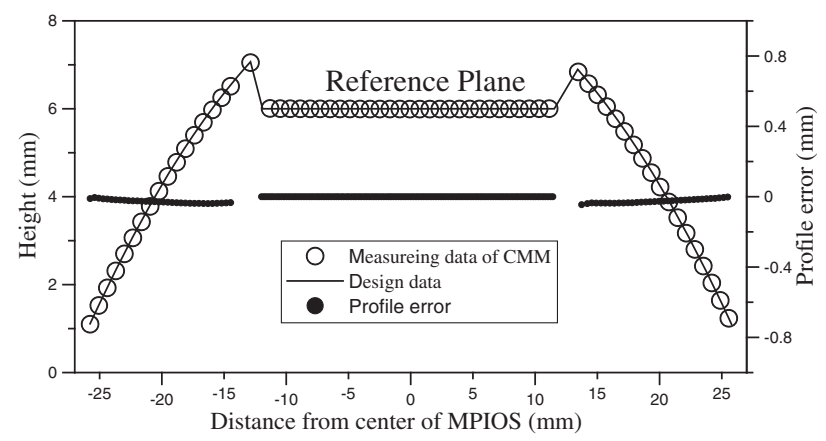

Fig. 6. Comparison of surface profiles of measurement and design.

Decreasing temperature during the final cooling step caused the PIMOC to shrink. The WC mold adapted to compensate for shape shrinkage. Figure 6 shows the finished upper surface profiles measured using the coordinate measuring machine $(\mathrm{CMM})$. A comparison between design and measurement profiles is also shown in Fig. 6. The upper plane of PIMOC was the reference plane; therefore, the comparison value of profiles around the center was zero. The measured profile results adheres to the design values.

\section{Conclusions}

This paper presents the fabrication of the PIMOC on NBK7 material using PGMT. Compared with the traditional CNC grinding process, the PGMT method was more timeefficient. The optimum parameters, molding temperature and molding pressure, were about $750^{\circ} \mathrm{C}$ and $2.75 \mathrm{kN}$ in PGMT for N-BK7 samples. Additionally, PGMT removed PIMOC bubbles and cracks when the cooling rate was set below $50^{\circ} \mathrm{C} / \mathrm{min}$ in a vacuum molding environment. The experiment showed that the fill rate of PIMOC reached $100 \%$ using PGMT, so the PIMOC can be mass-produced at high quality.

\section{References}

1) Y. C. Tsai, C. Hung, and J. C. Hung: J. Mater. Process. Technol. 201 (2008) 751.

2) T. Mori, K. Hasegawa, T. Hatano, H. Kasa, K. Kintaka, and J. Nishii: Jpn. J. Appl. Phys. 47 (2008) 4746.

3) A. Y. Yi and A. Jain: J. Am. Ceram. Soc. 88 (2005) 579.

4) H. J. Kim, H. U. Kim, S. S. Kim, Y. P. Park, J. H. Kim, and D. H. Cha: Opt. Rev. 14 (2007) 145.

5) H. Kikuta, H. Toyota, and W. Yu: Opt. Rev. 10 (2003) 63.

6) C. Y. Huang, K. C. Huang, J. C. Chen, K. S. Chang, S. F. Tseng, and C. P. Chou: Proc. Advances in Materials and Processing Technologies Conf., 2009, p. 11.

7) K. J. Ma: Precision Manufacturing and Inspection of Optical Components (Instrument Technology Research Center, Hsinchu, 2007) 1st ed., p. 223 [in Chinese]. 